\title{
The Time of Perception and the Other Way Around
}

\author{
Marcus Vinícius C. Baldo, André M. Cravo, and Hamilton Haddad \\ University of São Paulo (Brazil)
}

\begin{abstract}
The world we perceive is delayed in relation to its flowing content, as well as the outcome of our actions on the world in relation to the moment we decide to act. This mosaic of different latencies permeating both perception and action has to be taken into account critically in order for us to cope with the temporal challenges constantly imposed by the environment. Fundamental notions, such as the sense of agency and causality, depend on the temporal relationship of events occurring in well-defined windows of time. Here, we offer a broad, yet abridged, historical view of some thought-provoking issues concerning the time of perception and action. From the pioneering work of Wundt, Titchener, and Libet to recent findings and ideas related to the employment of visual illusions as psychophysical probes (such as the flash-lag effect), we have tried to expose some problems inherent to the act of measuring the time of both perception and action, and devise possible solutions as well.

Keywords: flash-lag effect, time of perception, time of action, intentional binding
\end{abstract}

El mundo que percibimos está retardado en relación a su flujo de contenido, al igual que el resultado de nuestras acciones sobre el mundo en relación con el momento en que decidamos actuar. Este mosaico de diferentes latencias que penetra tanto en la percepción como en la acción debe ser tenido en cuenta de forma crítica para poder manejar los retos temporales constantemente impuestos por el entorno. Nociones fundamentales, como el sentido de ser un agente y el de la causalidad, dependen de la relación temporal de los eventos que ocurren en ventanas bien definidas de tiempo. Aquí ofrecemos un panorama histórico extenso pero abreviado de algunas cuestiones provocadoras de la reflexión acerca del tiempo de la percepción y de la acción. Desde los trabajos pioneros de Wundt, Titchener y Libet hasta los descubrimientos recientes y las ideas relacionadas con el empleo de las ilusiones ópticas tales como el efecto "flash-lag", como sondas psicofísicas, hemos intentado exponer algunos de los problemas inherentes al acto de medir el tiempo, tanto el de la percepción como el de la acción, así como diseñar soluciones posibles.

Palabras clave: el efecto flash-lag, el tiempo de percepción, el tiempo de acción, ligado intencional

Correspondence concerning this article should be addressed to Marcus Vinícius C. Baldo, "Roberto Vieira" Sensory Physiology Lab, Department of Physiology and Biophysics, Institute of Biomedical Sciences, University of São Paulo, São Paulo, Brazil. E-mail: baldo@icb.usp.br 
When we look at a starry sky, we see a world that never existed in that way: many stars we still see died long ago, before others were born. The time elapsed since a photon leaves a star until it reaches our retinas varies from a few to billions of years. Surprisingly, although on a different scale, the same holds true for our daily life: the face we see, the voice we hear, and the hand we touch at the same time, engender sensory signals that take different times to travel throughout our neural processing stages, from receptors to the brain, before a bound and unitary percept is created. Moreover, transmission delays are by no means a feature inherent to perceptual processing only but are an integral component of motor behaviors as well.

On the one hand, behavioral timing is a crucial issue in survival, as adaptive success may depend on reasonably accurate judgments of temporal order and durations, as well as on precisely timed motor commands. On the other hand, differential transmission and processing latencies create a mosaic of temporal patterns spreading through the pathways and networks underlying both perception and action. A fundamental question thus immediately arises: How can we deal with such unrelated latencies in order to cope with the temporal challenges constantly imposed by the environment? We could split the above question into two. The first half addresses the generation of prompt skilled actions, which might involve predictive and automatic mechanisms, usually quite independent of conscious scrutiny but strongly dependent on previous learning experience. The second half of the question tackles the recognition that perception not only lags behind sensory reality but does it by spreading itself over a blend of temporal delays. For example, in a large concert hall, not only is all we perceive delayed in relation to the stimulating sources but also the asynchrony between what we see and what we hear might reach up to $400 \mathrm{~ms}$ (Durgin \& Sternberg, 2002; Pöppel, 1997).

The psychology — and metaphysics - of time perception has a long and enthralling history. In the eighteenth century, astronomers experienced better than anyone else the difficulties in measuring the very instant of time when an event takes place. Using the so-called "eye and ear" method, they recorded the precise positions of celestial events. This method consisted of measuring the moment when a particular star crossed the meridian marker of a telescope, with the time instant of stellar crossing being estimated by counting the audible ticking of a pendulum clock. Spatial interpolation was then used to estimate the moment of transit in tenths of seconds.

Large discrepancies between trained astronomers often resulted in significant measurement errors and this variability led to the formulation of a "personal equation" to try to correct this problem (Boring, 1929). The link between astronomy and psychology was made by the father of experimental psychology (or physiological psychology, as he named it), Wilhelm Wundt (Schmidgen, 2003, 2005).
Using a pendulum apparatus (Figure 1), he designed an experimental setup inspired by the eye and ear method. In a series of experiments, subjects had to judge the position of a fast moving clock hand when a brief click was presented. Wundt showed that participants systematically misperceived the position of the hand, perceiving it ahead or before the true position (the position where the hand physically was when the click was presented), depending on the experimental conditions. This was the prime example of a "complication experiment," characterized by involving the perceptual comparison of a continuous and a sudden event. Wundt's results could be accounted for by invoking either differences between visual and auditory perceptual latencies or different strategies adopted by the observers; more precisely, to which of the two events, visual or auditory, the observer was paying attention during the task. Among others, these findings led Titchener (1908) to formulate the law of prior entry: "the object of attention comes to consciousness more quickly than the objects which we are not attending."

As we shall see, these two kinds of accounts - differential latencies and attention-are nowadays still offered as explanations of the outcomes of related psychophysical tasks used to assess the spatiotemporal features of sensory perception, such as the flash-lag effect (FLE) and temporal order judgments (TOJ). In psychophysical tasks involving either the FLE or TOJ, we can often observe large shifts in the psychometric functions, in comparison to the accompanying thresholds, which characterize them as true illusions (Klein, 2002). Whereas an illusion arising from a TOJ is purely temporal, the FLE represents, as we will see next, a perceptual illusion in space and time.

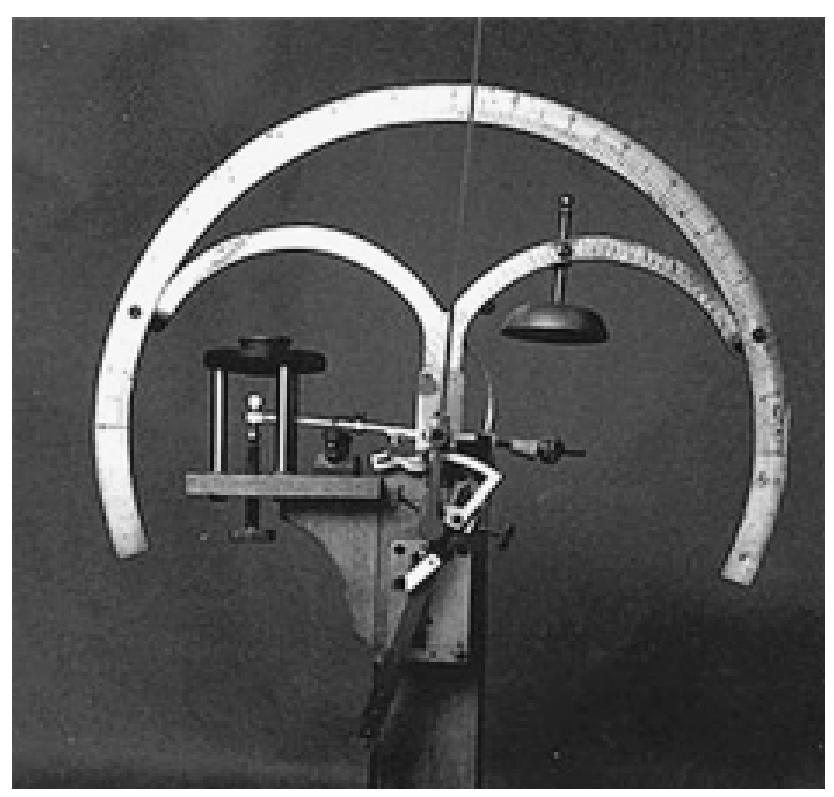

Figure 1. Wundt's pendulum apparatus used in "complication experiments" (from www.psichi.org/pubs/articles/article_457.asp) 


\section{Illusions in Space-Time}

\section{The Flash-Lag Effect}

As mentioned above, recurring disagreement between the measurements made by different astronomers at that time, led to the proposal that perceptual discrepancies might arise from the relative sharing of attention split between visual and auditory stimuli (Spence, Shore, \& Klein, 2001). In a more contemporary and prosaic scenario, assistant referees often make mistakes during soccer games when judging the relative location of an attacking player at the moment the ball touches or is passed by one of his or her teammates (Baldo, Ranvaud, \& Morya, 2002).

The common root of the above examples (and of any complication experiment in general) is the need to perform a dual task: where is the moving object (star or player) when the time-marker was presented (a given tick or pass). This question is intrinsically spatial and temporal in its very essence. In the midst of a variety of other visual illusions arising from the same question, the flash-lag effect (FLE) stands out as a still intriguing perceptual phenomenon, hotly debated over the last 12 years (Baldo \& Klein, 1995; Eagleman, 2001; Eagleman \& Sejnowski, 2000; Krekelberg \& Lappe, 2001; Lappe \& Krekelberg, 1998; Nijhawan, 1994, 2002; Nijhawan \& Khurana, 2000; Purushothaman, Patel, Bedell, \& Ogmen, 1998; Schlag \& Schlag-Rey, 2002; Whitney, 2002). In the FLE, a stationary flash is perceived as spatially lagging behind a moving object, despite their being physically aligned to each other at that moment (Figure 2).

The FLE, in fact an almost 100-year-old illusion (Fröhlich, 1923; Mackay, 1958; Metzger, 1931), was rediscovered in new clothing by Romi Nijhawan (Nijhawan, 1992, 1994). Nijhawan originally interpreted the flash-lag effect as resulting from a spatial extrapolation of the moving object ("motion extrapolation"), owing to the predictability of its trajectory. The perceptually extrapolated position of a moving object would thus compensate for the spatial error introduced by delays occurring throughout the visual system.

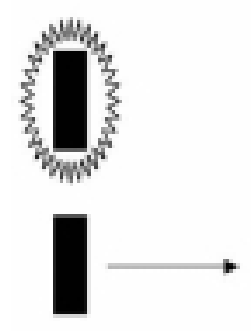

(A)

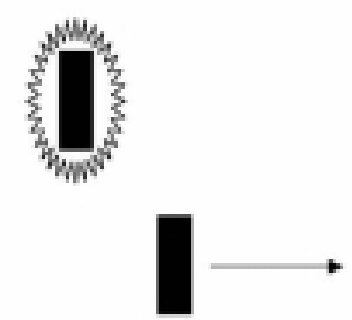

(B)
Figure 2. Schematic representation of the flash-lag effect. (A) The flashing stimulus is presented physically aligned to the moving one. (B) The subjects' perception of their relative locations, in which the flash is seen as lagging the moving stimulus.
In 1995, the first challenge to Nijhawan's explanation was put forward by Baldo and Klein. It was then demonstrated that the magnitude of the FLE was dependent not only on the features of the moving object (such as its speed), as previously shown by Nijhawan, but on the visual eccentricity of the stationary flash as well. This finding was at odds with the underpinnings of the motion extrapolation hypothesis. At that time, we interpreted the FLE "as resulting from a longer time delay involved in the visual processing of the flashing dots" (Baldo \& Klein, 1995). We proposed that some amount of time, dependent on eccentricity, is required to bring the flashing stimulus to a sufficiently high degree of perceptual processing for a snapshot of the moving stimulus to be taken. Three years later, three independent groups reported empirical findings that, yet again, did not fit in he motion extrapolation scheme. These authors showed, for instance, the robust dependence of the FLE on the trajectory of the moving stimulus (Lappe \& Krekelberg, 1998; Whitney \& Murakami, 1998) as well as on the luminance of both moving and stationary stimuli (Lappe \& Krekelberg; Purushothaman et al., 1998). From then on, the way was paved for a multitude of different approaches, views, and accounts concerning the flash-lag phenomenon (for reviews, see Eagleman, 2001; Krekelberg \& Lappe, 2001; Nijhawan, 2002; Nijhawan \& Khurana, 2000; Schlag \& Schlag-Rey, 2002; Whitney, 2002).

Our first demonstration of a putative role of visual attention in forging the flash-lag effect was based on a rather hazy empirical foundation (Baldo \& Klein, 1995). The main idea was centered on the time delay required to shift attention from the flashing stimulus' location to the moving stimulus' pathway, in order to make a spatial judgment of their relative locations. The influence of visual eccentricity on attentional shifts was, however, confounded with its even stronger influence on basic sensory issues, such as temporal latencies and spatial resolution. Later on, we were able to refine our analysis, providing more convincing support to the contribution of visual attention to the FLE. The magnitude of the FLE was shown to be modulated by the spatial predictability of the flashing stimulus (Baldo, Kihara, \& Klein, 2000; Baldo, Kihara, Namba, \& Klein, 2002; Baldo \& Namba, 2002) and its symbolic cueing as well (Namba \& Baldo, 2004). Moreover, a modulatory role of either bottom-up or top-down deployment of attention was recently implemented in a simple feed-forward neural network (Baldo \& Caticha, 2005), which was able not only to replicate a long list of empirical findings but also to encapsulate, in a unifying perspective, the main current accounts concerning the FLE.

\section{Temporal Order Judgment}

If we cannot determine the absolute timing of a subjective experience, all that can be done is to compare the relative timing of different experiences. This comparison is carried out in perceptual tasks involving temporal order 
judgments (TOJ), in which a pair of near-simultaneous stimuli are presented and observers are asked to judge which of them came first (Allan, 1975; James, 1890; Jaskowski, 1991; Spence et al., 2001; Sternberg \& Knoll, 1973; Ulrich, 1987). The idea behind TOJ manipulation is that one stimulus of the pair could receive some kind of perceptual priority that would alter the time it takes to reach awareness. The factors that establish this perceptual priority could be grouped into pre-attentive and attentive processes (Haddad, Carreiro, \& Baldo, 2002). Pre-attentive, or sensory, factors comprise some basic features of the sensory stimulus, such as its physical intensity or visual eccentricity (Haddad, Klein, \& Baldo, 1999).

Attention is also assumed to influence the speed with which a stimulus will reach consciousness (Stelmach \& Herdman, 1991), in line with the idea that the sensory information originating from an attended stimulus reaches some critical point in neural processing prior to the information arising from an unattended stimulus (Jaskowski, 1993; Stelmach \& Herdman). Recently, the role of attention in temporal order perception has been investigated by means of the simultaneous measures of TOJ and event-related potential (ERP) recordings in the human visual cortex (McDonald, Teder-Sälejärvi, Russo, \& Hillyard, 2005). These investigators observed that attention enhanced the amplitude of neural activity in the visual cortex, showing that attentioninduced shifts in time-order perception probably arise from modulations of signal strength rather than from processing speed in the early sensory pathways.

\section{The Time of Perception}

The archetype of striking results obtained by employing TOJ and complication experiments (such as those leading to the FLE) is found in the seminal work carried out by Benjamin Libet and collaborators (Libet, 2002, 2004; Libet, Wright, Feinstein, \& Pearl, 1979). Working with patients undergoing neurosurgical procedures, Libet and his group assessed latencies involved in both perception and action (see also the next section, The Time of Action). Their findings have been pungently debated since then, which has contributed to a clarification of concepts and interpretations related to the phenomenology of time in perception as well in action.

In a series of experiments, Libet and his group (Libet, Wright, Feinstein, \& Pearl, 1979) compared the time of sensations arising from the electrical stimulation of the subject's hand with the time of sensations caused by the direct electrical stimulation of the exposed somatossensory cortex (Figure 3). The delay involved in eliciting a sensation by means of a peripheral and natural stimulus includes the signal transmission through sensory pathways and the completion of a sequence of neural events in higher areas of the nervous system (which Libet called "neural adequacy"). Given that this latency, measured in previous experiments, is of hundreds of milliseconds, Libet and his colleagues expected the patients to report, for the stimuli presented simultaneously, that the cortical stimulation could be felt first. In fact, the inverse was observed, even in instances in which the cortex was stimulated before the hand. Libet and colleagues interpreted their results by proposing that the sensations evoked by the skin stimulation were referred "backward" to the time of the stimulus (Libet, 2002, 2004; Libet et al.; see also, on this topic, the special issue of Conscious and Cognition, Volume 11, 2002).

Libet's findings and interpretations instilled some furor in the scientific arena, and were taken at face value by some scientists either to substantiate exotic physical proposals (Penrose, 1989) or to lend support to a dualist view of the neurosciences (Popper \& Eccles, 1983). On the other hand, Libet's work has been also severely criticized on both methodological and interpretational grounds (Churchland, 1981, 1986; Glynn, 1990; Gomes, 1998, 2002; Klein, 2002; Pocket 2002). A special kind of criticism, akin to the present discussion, concerns the representation of time by our brains (Dennett, 1991; Dennett \& Kinsbourne, 1992; Glynn).

As sustained by the philosopher Daniel Dennett (Dennett, 1991; Dennett \& Kinsbourne, 1992) and by the physiologist Ian Glynn (1990), the brain does not have to use time to represent time itself. Therefore, it would be improper to identify the perception of an event's occurrence time with the time when we become conscious of it. That is, it is not necessary to postulate an isomorphism between the temporal order of the brain processes and the represented temporal order of events in the world. Instead of this, the nervous system would simply add time markers (or "stamps") on

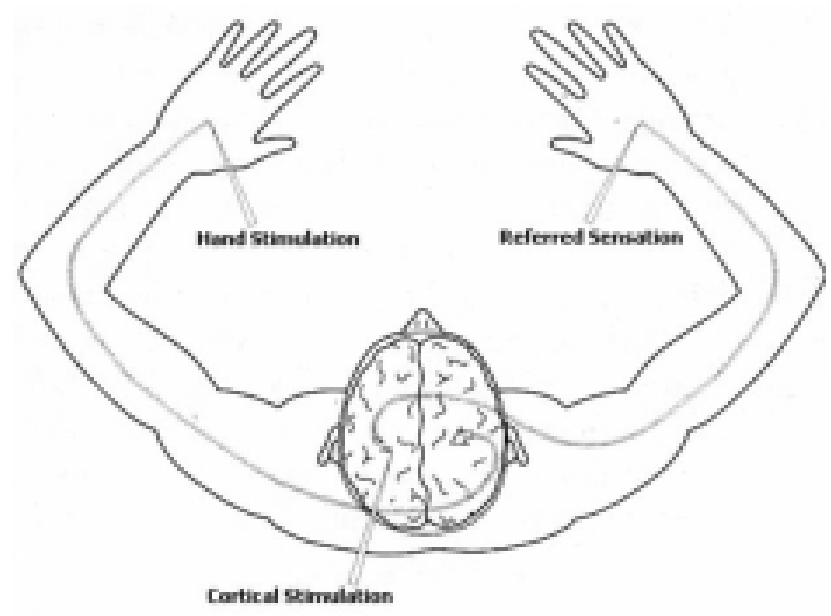

Figure 3. Schematic representation of Libet's experimental procedure. The sensory stimulus applied to the left hand elicits a neural activation in the contralateral (right) somatossensory cortex. By its turn, the direct stimulation of the left somatossensory cortex is reported to be felt in the contralateral (left) hand (modified from Dennett, 1991). 
sensory inputs early in the series of neural events related to the conscious perception of these inputs. When asked to judge the time of occurrence of a given stimulus, subjects could use these markers to order a sequence of mental events. This approach remits to Dennett's "content-vehicle" distinction. As an example, we can consider what happens when we receive a letter from the post office. If we are interested in the time at which the events (content) in the letter (vehicle) occurred, we look at the date on the letter (time of content) rather than consider the date at which it was delivered (time of vehicle). This line of reasoning is quite similar to the "postdiction" account, devised by Eagleman and Sejnowski (2000) in order to explain the flash-lag effect. According to these views, perception is not an "on-line" process, but "postdicted" to the instant of relevant time-markers.

\section{The Time of Action}

In 1983, based on his earlier research, Libet and collaborators started a sequence of classical experiments that aimed to measure the occurrence time of a voluntary motor decision (Libet, 1985, 2004; Libet, Gleason, Wright, $\&$ Pearl 1983). They did this by asking the subject to report the perceived location of a clock's hand at the moment the urge to move was felt and also when the movement was felt to be executed. Their main findings were that a specific electrical signal observed in brain activity, called readiness potential (RP), occurred about $500 \mathrm{~ms}$ before the voluntary act, whereas the subjective feeling of the urge to act was reported roughly $150 \mathrm{~ms}$ before the voluntary act. According to Libet, these results indicate that the brain starts the voluntary process before the subject becomes consciously aware of the urge or wish, and the RP would be correlated with the conscious intention. Haggard and Eimer (1999), using a modification of Libet's paradigm found that the lateralized readiness potential (LRP) is more likely to be the correlate of conscious intention, rather than the RP. The LRP is the point at which activity in the hemisphere contralateral to the selected hand exceeds the ipsilateral activity associated with the non-selected hand. These results would indicate that conscious intention is linked to the specific preparation to perform a particular movement and not to the earliest neural preparation to action. Though the results found by Libet have had a long and often controversial history, an important contribution of these results is the suggestion that before we became aware of our intentions, several processes have already taken place in our brain.

More recent psychophysical studies, employing a procedure similar to Libet's, have demonstrated that being agent of an event might affect the perceived time of such event (Haggard, Clark, \& Kalogeras, 2002). In their experiments, Haggard and colleagues asked subjects to indicate the perceived time of either their actions or a beep evoked by their action after a $250 \mathrm{~ms}$ delay. These results were compared with blocks in which the subjects judged either an action that did not evoke a beep, or a beep that occurred without action. They found that subjects perceived their action as shifted in time towards the beep that it caused, and perceived the beep as shifted earlier in time towards the action that caused it (Figure 4). In further experiments they added a delay between the key press and the evoked beeps. The results showed that this binding decreases as the interval between action and effect increases. Additionally, this binding effect is modulated by temporal contiguity and temporal predictability and these authors refer to this linkage as intentional binding (for a review, see Haggard, 2005).

An issue that arises is what mechanisms might be involved in intentional binding. A possible explanation would be based on feed-forward models. In 1950, Roger Sperry proposed that when a motor command is sent to the muscles, an efferent copy (also known as "corollary discharge") is also sent to the sensory areas of the brain. This efferent copy would reduce the latency of the stimulus caused by the subject. Apparently, even organisms as simple as arthropods have such a mechanism (Webb, 2004). More recently, several feed-forward models based on efferent copies have been proposed in order to explain certain aspects of motor performance, such as motor planning, prediction, and learning (Wolpert, 1997). The main assumption of these models is that the preparation of a movement would include an efferent copy sent to an internal predictive model (Figure 5). This model estimates the effect of the motor commands, allowing more rapid adjustments and more fluent movement. Although these models were originally proposed to explain motor performance, they became valuable to understand which components of action are conscious, and which are unconscious.

Other possibilities for intentional binding might be suggested. As we discussed previously, attention is known to have an important influence on the perception of an event's occurrence time, shifting the perception of an

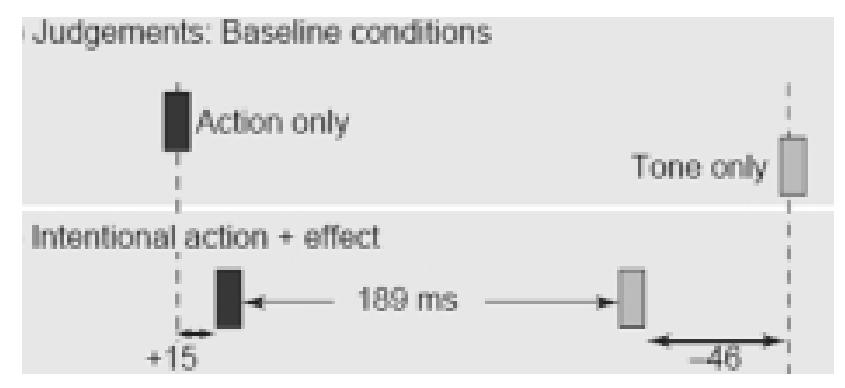

Figure 4. Intentional binding between voluntary actions and their effects. When action and tone occur together, the perceived time of the action shifts forwards in time from the baseline value, towards the tone. The perceived time of the tone shifts earlier in time, towards the action. Action and tone are bound together across time, implying a reduction in the perceived interval between them (modified from Haggard, 2005). 


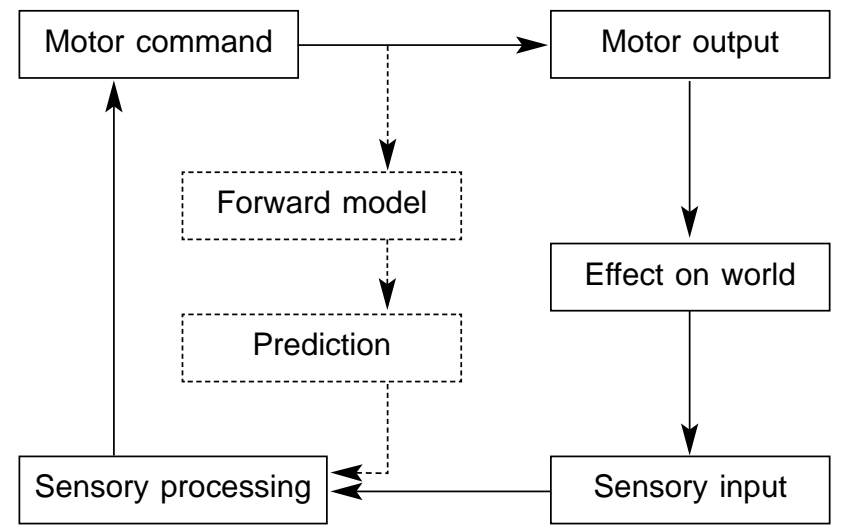

Figure 5. Schematic representation of a forward model. The forward model assumes the operation of an internal loop (broken lines) that leads the motor command to generate the anticipation of sensory changes, which can be then used to modulate the processing of the ongoing input (adapted from Webb, 2004).

attended event to an earlier instant in time. When one causes a stimulus, its temporal predictability can be considered as the highest possible (Eagleman \& Holcombe, 2002), which might reduce its perceptual latency. This attentional hypothesis differs from Haggard's proposal. According to him, the binding of action and its effect is a result of specific cognitive functions of our central nervous system, rather than a consequence of attentional processes. As for the attentional account, the preparation of a movement would include the allocation of attentional resources to both the expected sensory consequences and the time of execution of the movement itself. Again, we enter the question as to whether our nervous system utilizes time to encode time: Does the stimulus caused by the subject reach some neuronal population faster than a computer-generated stimulus because of some neural facilitation, or does our brain represent a self-produced stimulus in such a way that is later interpreted as occurring before in time? Although these processes might occur later in our perception, the facilitation may be due to processes that begin with the specific preparation of an action. Here too, we can see that the flash-lag effect can also be used as a useful tool to investigate the relationship between perception and action. As recently shown by Joan López-Moliner and Daniel Linares $(2005,2006)$, and also by us (Haddad \& Baldo, 2005), when the time-marker (flash) is triggered by an active observer, the magnitude of the flash-effect, given by the relative location between the flash and a moving stimulus, is reduced when compared to a passive condition, in which the flash is not actively triggered. These results make clear the influence of action on spacetime perception, although still not uncoupling attentional modulation from other cognitive mechanisms.

\section{Conclusion}

Besides acting on the world we live in, we struggle to make sense of it. Actually, to perceive the world is to build mental models (representations) that should be useful in planning future actions. Therefore, we could say that our actions (as well as our ancestors' actions) shape our perceptions. Similarly to the paramount role of timing in planning and executing adaptive actions, timing is also crucial to mold the final content of our perceptions. For instance, the natural and crystal-clear sense of causality depends on narrow temporal correlations between perceived events. Another vital notion, our sense of agency also depends on temporal correlations between what we perceive from the world and what we perceive from our own actions. Therefore, the physical timing of events is translated to the neural timing of neuronal processes, which is then somehow represented as a particular mental timing of experiential percepts (van de Grind, 2002).

In this paper, we have tried to show some problems inherent to the act of measuring the time of perception and action. Except for TOJ procedures, in which the comparisons are made between two abrupt events, in most cases, the comparison takes place between an abrupt event and a moving one (even when motion does not happen in the usual physical space, but within a more abstract perceptual space). It happened in Wundt's, Libet's and Haggard's experiments, as described above, as well as in all procedures leading to the flash-lag phenomenon: the instant of occurrence of a sudden stimulus (the occurrence instant that one wants to measure) must be matched with the course of some temporal variable in continuous flow. It happens all the time in daily situations: for instance, as when someone asks us what time is it now. To provide this information, we have to look at the clock (which takes time) and then the very instant we intended to grasp has already passed. In the same way, in the experiments discussed here, our nervous system had to deal with the task of comparing the neural activity related to an abrupt event with the ongoing neural activity related to an event "moving" in sensory space. At least, this process should require an attentional shift from the abrupt-neuralactivity to the moving-neural-activity and would, therefore, spend some amount of time. Hence, we are faced to a general problem concerning every attempt to measure the particular instant of occurrence of a perceptual event. This is a tremendous challenge because, as we saw, fundamental difficulties arise whenever subjects have to perceptually crystallize an instant of time.

As a last remark, we should not overlook the very essence of time, with its physical and metaphysical meanings. These aspects are to be included in any serious debate on the relationship between time and perception; otherwise we could come up, for example, with the following original conclusion: "there are three times, [...] for these three exist in the mind, and I find them nowhere else: the 
present of things past is memory, the present of things present is sight, the present of things future is expectation." Although these words may sound quite contemporary and, as a matter of fact, they may express current views on time perception, they were stated by St. Augustine about 1600 years ago.

\section{References}

Allan, L.G. (1975). The relationship between judgments of successiveness and judgments of order. Perception and Psychophysics, 18, 29-36.

Baldo, M.V.C., \& Caticha, N. (2005). Computational neurobiology of the flash-lag effect. Vision Research, 45, 2620-2630.

Baldo, M.V.C., Kihara, A.H., \& Klein, S.A. (2000). Lagging behind because of sensory and attentional delays. [Abstract] Investigative Ophthalmology and Visual Science, 41, S420.

Baldo, M.V.C., Kihara, A.H., Namba, J., \& Klein, S.A. (2002). Evidence for an attentional component of perceptual misalignment between moving and flashing stimuli. Perception, 31, 17-30.

Baldo, M.V.C., \& Klein, S.A. (1995). Extrapolation or attention shift? Nature, 378, 565-566.

Baldo, M.V.C., \& Namba, J. (2002). The attentional modulation of the flash-lag effect. Brazilian Journal of Medical and Biological Research, 35, 969-972.

Baldo, M.V C., Ranvaud, R.D., \& Morya, E. (2002). Flag errors in soccer games: The flash-lag effect brought to real life. Perception, 31, 1205-1210.

Boring, E.G. (1929). A history of experimental psychology. New York: Appleton-Century.

Churchland, P. (1981). On the alleged backwards referral of experiences and its relevance to the mind-body problem. Philosophy of Science, 48, 165-181.

Churchland, P. (1986). Neurophilosophy: Toward a unified science of the mind-brain. Cambridge, MA: MIT Press.

Dennett, D. (1991). Consciousness explained. Boston: Little, Brown \& Co.

Dennett, D., \& Kinsbourne, M. (1992). Time and the observer: The where and when of consciousness in the brain. Behavioral Brain Science, 15, 183-247.

Durgin, F.H., \& Sternberg, S. (2002). The time of consciousness and vice versa. Consciousness and Cognition, 11, 284-290.

Eagleman, D.M. (2001). Visual illusions and neurobiology. Nature Neuroscience, 2, 920-926.

Eagleman, D.M., \& Holcombe A.O. (2002). Causality and the perception of time. Trends in Cognitive Sciences, 6, 323-325.

Eagleman, D.M., \& Sejnowski, T.J. (2000). Motion integration and postdiction in visual awareness. Science, 287, 2036-2038.

Fröhlich, F.W. (1923). Über die Messung der Empfindungszeit. Zeitschrift für Sinnesphysiologie, 54, 58-78.

Glynn, I.M. (1990). Consciousness and time. Nature, 348, 477479.

Gomes, G. (1998).The timing of conscious experience: A critical review and reinterpretation of Libet's research. Consciousness and Cognition, 7, 559-595.
Gomes, G. (2002). Problems in the timing of conscious experience. Consciousness and Cognition, 11, 191-197. Haddad Jr., H., \& Baldo, M.V.C. (2005). The interference of action in the flash-lag effect. [Abstracts] Association for the Scientific Study of Consciousness, 9, 51.

Haddad Jr., H., Carreiro, L.R.R., \& Baldo, M.V.C. (2002). Modulation of perception of temporal order by attentional and pre-attentional factors. Brazilian Journal of Medical and Biological Research, 35, 979-983.

Haddad Jr. H., Klein, S., \& Baldo, M.V.C. (1999). The contribution of attentional and pre-attentional mechanisms to the perception of temporal order. In C. Taddei-Ferretti \& C. Musio (Eds.), Neuronal bases and psychological aspects of consciousness (pp. 339-342). Singapore: World Scientific.

Haggard, P. (2005). Conscious intention and motor cognition. Trends in Cognitive Sciences, 9, 291-295.

Haggard, P., Clark, S., \& Kalogeras, J. (2002). Voluntary action and conscious awareness. Nature Neuroscience, 5, 382-385.

Haggard, P., \& Eimer, M. (1999). On the relation between brain potentials and the awareness of voluntary movements. Experimental Brain Research, 126, 128-133.

James, W (1890). The principles of psychology. New York: Dover. Jaskowski, P. (1991). Two-stage model for order discrimination. Perception and Psychophysics, 50, 76-82.

Jaskowski, P. (1993). Temporal-order judgment and reaction time to stimuli of different rise times. Perception, 22, 963-970.

Klein, S.A. (2002). Libet's temporal anomalies: A reassessment of the data. Consciousness and Cognition, 11, 198-214.

Krekelberg, B., \& Lappe, M. (2001). Neuronal latencies and the position of moving objects. Trends in Neurosciences, 24, 335339.

Lappe, M., \& Krekelberg, B. (1998). The position of moving objects. Perception, 27, 1437-1449.

Libet, B. (1985). Unconscious cerebral initiative and the role of conscious will in voluntary action. Behavioral and Brain Sciences, 8, 529-566.

Libet, B. (2002). The timing of mental events: Libet's experimental findings and their implications. Consciousness and Cognition 11, 241-264.

Libet, B. (2004). Mind time: The temporal factor in consciousness. Boston: Harvard University Press.

Libet, B., Gleason, C.A., Wright Jr, E.W., \& Pearl, D.K. (1983). Time of conscious intention to act in relation to onset of cerebral activity (readiness-potential): The unconscious initiation of a freely voluntary act. Brain, 106, 623-642.

Libet, B., Wright, E.W., Feinstein, B., \& Pearl D.K. (1979). Subjective referral of the timing for a conscious sensory experience: A functional role for the somatosensory specific projection system in man. Brain, 102, 193-224.

Lopez-Moliner, J., \& Linares, D. (2005). Internal and external prediction in the flash-lag effect. [Abstracts] Vision Sciences Society $5^{\text {th }}$ Annual Meeting, 56.

Lopez-Moliner, J., \& Linares, D. (2006). The flash-lag effect is reduced when the flash is perceived as a sensory consequence of our action. Vision Research, 46, 2122-2129. 
Mackay, D.M. (1958). Perceptual stability of a stroboscopically lit visual field containing self-luminous objects. Nature, 181, 507508.

McDonald, J.J., Teder-Sälejärvi, A.T., Russo, F.D., \& Hillyard, S.A. (2005). Neural basis of auditory-induced shifts in visual time-order perception. Nature Neuroscience, 8, 1197 1202.

Metzger, W. (1931). Versuch einer gemeinsamen Theorie der Phänomene Fröhlichs und Hazelhoffs und Kritik ihrer Verfahren zur Messung der Empfindungszeit. Psychologische Forschung, 16, 176-200.

Namba, J., \& Baldo, M.V.C. (2004). The modulation of the flashlag effect by voluntary attention. Perception, 34, 621-631.

Nijhawan, R. (1992). Misalignment of contours through the interaction of apparent and real motion systems. [Abstract] Investigative Ophthalmology and Visual Sciences, 33, 1415.

Nijhawan, R. (1994). Motion extrapolation in catching. Nature, 370, 256-257.

Nijhawan, R. (2002). Neural delays, visual motion and the flashlag effect. Trends in Cognitive Sciences, 6, 387-393.

Nijhawan, R., \& Khurana, B. (2000). Conscious registration of continuous and discrete visual events. In T. Metzinger (Ed.), Neural correlates of consciousness: Empirical and conceptual questions (pp. 203-219). Cambridge, MA: MIT Press.

Penrose, R. (1989). The emperor's new mind. Oxford, UK: Oxford University Press.

Pocket, S. (2002). On subjective back-referral and how long it takes to become conscious of a stimulus: A reinterpretation of Libet's data. Consciousness and Cognition, 11, 144-161.

Pöppel, E. (1997). A hierarchical model of temporal perception. Trends in Cognitive Science, 1, 56-61.

Popper, K.R. \& Eccles, J.C. (1983). The self and its brain. London: Routlege.

Purushothaman, G., Patel, S.S., Bedell, H.E., \& Ogmen, H. (1998). Moving ahead through differential visual latency. Nature, 396, 424.

Schlag, J., \& Schlag-Rey, M. (2002). Through the eye, slowly: Delays and localization errors in the visual system. Nature Reviews Neuroscience, 3, 191-200.
Schmidgen, H. (2003). Time and noise: The stable surroundings of reaction experiments, 1860-1890. Studies in history and philosophy of science Part C: Studies in history and philosophy of biological and biomedical sciences, 34, 237-275.

Schmidgen, H. (2005). Physics, ballistics, and psychology: A history of the chronoscope in/as context, 1845-1890. History of Psychology, 8, 46-78.

Spence, C., Shore, D.I., \& Klein, R.M. (2001). Multisensory prior entry. Journal of Experimental Psychology: General, 4, 799-832.

Sperry, R.W. (1950). Neural basis of the spontaneous optokinetic response. Journal of Comparative Physiological Psychology, 43, 482-489.

Stelmach, L.B., \& Herdman, C. (1991). Directed attention and perception of temporal order. Journal of Experimental Psychology: Human Perception and Performance, 17, 539-550.

Sternberg, S., Knoll, R.L. (1973). The perception of temporal order: Fundamental issues and a general model. In S. Kornblum (Ed.), Attention and performance IV (pp. 629-685). New York: Academic Press.

Titchener, E.B. (1908). Lectures on the elementary psychology of felling and attention. New York: Macmillian.

Ulrich, R. (1987).Threshold models of temporal-order judgments evaluated by a ternary response task. Perception \& Psychophysics, 42, 224-239.

van de Grind, W. (2002). Physical, neural, and mental timing. Consciousness and Cognition, 11, 241-264.

Webb, B. (2004). Neural mechanisms for prediction: Do insects have forward models? Trends in Neuroscience, 27, 278-282.

Whitney, D. (2002). The influence of visual motion on perceived position. Trends in Cognitive Sciences, 6, 211-216.

Whitney, D., \& Murakami, I. (1998). Latency difference not spatial extrapolation. Nature Neuroscience, 1, 656-657.

Wolpert, D.M. (1997). Computational approaches to motor control. Trends in Cognitive Sciences, 1, 209-216.

Received December, 11, 2006

Revision received May, 16, 2007 Accepted July, 24, 2007 